\title{
BASIS FOR RELIABILITY ASSESSMENT OF INDUSTRIAL HERITAGE BUILDINGS AND A CASE STUDY OF A 19TH CENTURY FACTORY
}

\author{
J. MARKOVA, M. HOLICKY, K. JUNG \& M. SYKORA \\ Klokner Institute, Czech Technical University in Prague, Czech Republic.
}

\begin{abstract}
Considerable efforts are aimed at re-using industrial heritage buildings in order to preserve their heritage value, revive declining regions and avoid wasting energy. Such buildings hardly fulfil the requirements of present standards for structural design. Decisions about construction interventions should be based on the complex assessment of a structure considering actual material properties, environmental influences and satisfactory past performance. Simplified conservative procedures accepted for structural design often lead to expensive repairs and losses of heritage value. The probabilistic procedure in accordance with ISO 13822 for assessment of existing structures can considerably enhance reliability verification. Application of theoretical principles is illustrated by the case study of a 19th-century spinning factory, listed as industrial heritage. The actual characteristics of a cast-iron structure are verified by material tests, measurements of geometry and careful visual inspection. Actual behaviour of an existing structure and the previous load history is considered when deciding about its further use and rehabilitation. The case study indicates that the probabilistic methods can be effectively applied in reliability verifications of heritage buildings and decisions about construction interventions.

Keywords: cast iron, construction interventions, decision making, heritage value, industrial heritage, probabilistic assessment.
\end{abstract}

\section{INTRODUCTION}

A number of factories, warehouses, power plants and other industrial buildings were built during the Industrial Revolution and have been registered as industrial cultural heritage throughout the world. Such structures are mostly of significant architectural, historical, technological or social value $[1,2]$. Protection - including adaptations and re-use - of these structures is an important issue, positively contributing to the sustainable development of urban areas by:

- preserving cultural values - the heritage value of the structure commonly originates from its uniqueness, quality of craft execution, relationship with an important event or person, urban context, importance as a landmark etc.;

- recycling of potential resources and avoiding wasting energy;

- facilitating the economic regeneration of regions in decline.

However, insufficient attention seems to be paid to systematic recognizing, declaring and protecting of industrial heritage in most countries. This is an alarming situation as the lack of attention and awareness of such buildings gradually leads to their extinction.

When out of use and without proper maintenance, industrial heritage buildings are degrading and turning into ruins. Re-use and adaptation of industrial buildings to hotels, museums, residential parks and commercial centres help to protect cultural heritage and atmosphere of urban areas [3].

The protection of industrial heritage is a multidisciplinary topic which includes historical, architectonic, civil engineering and ecological aspects. In 1978 the International Committee 
on the Conservation of the Industrial Heritage (TICCIH) was founded to study, protect, conserve and explain remains of industrialization. The cooperation of TICCIH and the International Council on Monuments and Sites (ICOMOS) has resulted in registering more than 40 industrial-related sites in the World Heritage List. In the Czech Republic, the majority of construction works listed as industrial heritage date from the second half of the 19th century to the first quarter of the 20th century.

It has been recognized that many heritage structures fail to fulfil requirements of present codes of practice. Decisions about adequate construction interventions should be based on the complex assessment of a structure. Minimization of construction interventions is required in rehabilitation and upgrades, but sufficient reliability should also be guaranteed. Application of simplified procedures used for designing of new structures may lead to expensive repairs and losses of the heritage value. A general probabilistic procedure is thus proposed to improve the reliability assessment of industrial heritage buildings particularly with respect to:

- better description of uncertainties related to the assessment;

- facilitation of inclusion of results of inspections, tests, measurements and the experience based on satisfactory past performance of the structure.

Moreover, probabilistic assessment is an essential part of risk-informed decision making concerning safety measures [4]. Application of theoretical principles is illustrated by a case study of a 19th-century spinning factory, listed as industrial heritage.

\section{RELIABILITY ANALYSIS}

\subsection{General aspects}

As a rule, re-use and adaptation of industrial buildings require structural reliability assessment. However, it appears that insufficient attention has been paid by experts to the specific issues of such assessment so far. The following differences between the assessment and designing of new structures should be carefully taken into account:

- social and cultural aspects - the loss of heritage values

- economic aspects - additional cost of measures to enhance reliability of a heritage building in comparison with a new structure; at a design phase the cost of such measures is much lower than the cost of strengthening

- principles of the sustainable development - waste reduction and recycling of materials; these aspects are more significant in the case of an existing building

- lack of information for assessment - a limited number of tests restricted by protecting heritage values, even though such tests are vital due to the variability of mechanical properties, deterioration effects and damage that may have occurred during the working life of the structure

Significant uncertainties related to actual material properties and structural conditions usually need to be considered in reliability assessment. In standards for structural design, a limited number of safety factors are intended to cover all relevant design situations. Therefore, verifications based on procedures accepted for structural design may be overly conservative, resulting in expensive repairs and the loss of a heritage value. 
It has been recognized that the assessment of existing structures is a structure-specific task that is difficult to codify. In accordance with EN 1990 [5] and ISO 13822 [6], a probabilistic procedure is thus proposed here to enhance the reliability assessment of industrial heritage buildings. The procedure makes it possible to include results of inspections, testing, measurements and the experience based on satisfactory past performance of the structure. Probabilistic verification may be appropriate [7] in the following situations:

1. Detailed or little information on structural conditions is available.

2. There are significant uncertainties in actual structural performance and conditions exist.

3. Consequences of structural failure including the loss of a heritage value are high.

4. Evaluation of the efficiency of monitoring and maintenance strategies is required.

5. Fundamental decisions concerning a whole group of structures are needed.

In the case of heritage structures, the first three cases can be particularly relevant.

Uncertainties in the assessment of heritage structures are often greater than in the design of new structures; examples are the statistical uncertainty due to a limited amount of test data or uncertainties related to inaccessible members and connections where construction details cannot be inspected and verified. These uncertainties can be adequately described by probabilistic methods [8]. On the contrary, some of the uncertainties reflected - often implicitly in load and resistance factors (modelling approximations, deviations from specified dimensions and strengths) may be less than in new construction, particularly when in-situ measurements are taken.

\subsection{Models for basic variables}

Models for basic variables should be adjusted to the actual situation and state of a structure and verified by inspection and testing. The following principles should be taken into account:

- Material properties should be considered according to actual conditions of the structure and verified by destructive or non-destructive testing. It is often appropriate to combine limited new information with prior information. Bayesian techniques provide a consistent basis for this updating; details are provided in ISO 12491 [9] and in the materials of the Joint Committee on Structural Safety JCSS $[4,10]$. Prior information may be found in normative documents, scientific literature, reports of producers etc. For instance, the Czech standard CSN 73 0038:2014 - a former National Annex to ISO 13822 [6] - provides characteristics of different historical materials. Detailed information focused on industrial heritage buildings is given in the monograph [2].

- When significant deterioration is observed, an appropriate deterioration model should be used to predict changes in structural parameters due to foreseen environmental conditions, structural loading, maintenance practices and past exposures, based on theoretical or experimental investigation, inspection and experience.

- Dimensions of structural members should be determined by measurements. When the original design documentation is available and no changes in dimensions exist, nominal dimensions given in the documentation may be used.

- Load characteristics should be introduced considering the values corresponding to the actual situation. For structures with significant permanent actions, the actual geometry should be verified by measurements and weight densities should be obtained from tests. 
- Model uncertainties should be considered in the same way as at a design stage unless previous structural behaviour (especially damage) indicates otherwise. In some cases model factors, coefficients and other design assumptions can be established on measurements.

It follows that the reliability verification of a heritage building should be backed up by inspection and collecting appropriate data. Evaluation of prior information and its updating using newly obtained measurements may be a crucial step of the assessment.

\subsection{Probabilistic updating}

The failure probability, related to the period from the assessment to the end of a working life, $t_{\mathrm{D}}$, can be obtained from a general probabilistic relationship:

$$
p_{\mathrm{f}}\left(t_{\mathrm{D}}\right)=P\left\{\min \mathrm{Z}[\mathbf{X}(\tau)]<0 \text { for } 0<\tau<t_{\mathrm{D}}\right\}=\mathrm{P}\left\{F\left(t_{\mathrm{D}}\right)\right\}
$$

where $\mathrm{Z}(\cdot)$ is the limit state function; $\mathbf{X}(\cdot)$ is the vector of basic variables including model uncertainties, resistance, permanent and variable actions; and $F\left(t_{\mathrm{D}}\right)$ is the failure in the inter$\operatorname{val}\left(0, t_{\mathrm{D}}\right)$.

When additional new information, $I$, related to structural conditions becomes available, the failure probability can be updated according to ISO 13822 [6] as follows:

$$
p_{\mathrm{f}}\left(t_{\mathrm{D}} \mid I\right)=\mathrm{P}\left\{F\left(t_{\mathrm{D}}\right) \cap I\right\} / \mathrm{P}(I)
$$

Relevant information should be selected to maximize the correlation between the events $\{F\}$ and $\{I\}$. Strong correlation improves the posterior estimate of failure probability while weak correlation yields similar estimates as based on eqn (1); see [8]. The new information can result from:

1. inspections that can provide data for the updating of a deterioration model,

2. material tests and in-situ measurements that can improve the models of material or geometry properties,

3. consideration of the satisfactory past performance,

4. static and dynamic response to controlled loading including proof tests.

In the first two cases, the new information is usually applied in the direct updating of (prior) distributions of relevant basic variables that are commonly based on experience from assessments of similar structures, long-term material production, findings reported in literature or engineering judgement. The third case may be very important for industrial structures [11, 12]; for instance the structure, originally used as a factory and adapted to a museum or gallery, may have resisted loads much greater than those expected for a future use. The fourth case is substantially similar to the third one; structural response to controlled loading can reduce uncertainties in a resistance model; however, this procedure is applied in exceptional cases. More information on probabilistic updating is provided elsewhere $[4,13]$. 


\section{TARGET RELIABILITY}

Reliability verification can be based on either of the following equivalent relationships:

$$
p_{\mathrm{f}}\left(t_{\mathrm{D}} \mid I\right)<p_{\mathrm{t}}, \quad \beta\left(t_{\mathrm{D}} \mid I\right)=-\Phi^{-1}\left[p_{\mathrm{f}}\left(t_{\mathrm{D}} \mid I\right)\right] \geq \beta_{\mathrm{t}}
$$

where $p_{\mathrm{t}}$ is the target failure probability; $\Phi^{-1}$ is the inverse cumulative distribution function of the standardized normal variable; and $\beta_{\mathrm{t}}$ is the target reliability index.

Specification of target reliability levels is one of the key issues of the assessment of existing structures. ISO 13822 [6], ISO 2394 [14] and its second edition issued in 1998 indicate procedures for specifying target reliability levels by cost optimization and suggest acceptance criteria for human safety. Recent studies $[15,16]$ reveal that the requirement to reach the same target reliability levels for existing structures as for new structures is uneconomical. ISO 2394 [14] provides target levels based on economic optimization that might be appropriate for existing structures when large relative costs of safety measures are assumed. Note that lower costs of safety measures are commonly taken into account for design of a new structure.

Fundamental principles for the assessment of buildings and bridges with a cultural heritage value are provided in Annex I of ISO 13822 [6]. Such assessment shall reflect structural reliability and the heritage value of the structure, and these two aspects shall both be taken into account in any decision involving possible construction interventions. The heritage value is normally associated with character-defining elements - historic materials, forms, locations, spatial configurations, morphology, concept and details, structural design, uses and cultural associations that contribute to the heritage value of the structure, which shall be retained in order to preserve its heritage value.

Construction works or their load-bearing structures often represent an important aspect of the culture of a certain time period. Besides this, the structures can support other characterdefining elements such as technologies, facades or other non-structural members including historic mural paintings.

To retain authenticity and integrity, the structure is to be preserved, as far as possible, with its original or similar materials and structural concept. Unnecessary construction interventions may result in excessive costs, may hinder the viability of rehabilitation and consequently they may endanger the heritage value and the existence of the building.

Heritage values of industrial buildings depend on the cultural and historic conditions of different regions within a country, Europe, or throughout the world. At present, no generally valid criteria for the assessment of heritage structures exist and such assessments are as a rule based on a case-specific approach. The criteria related to heritage values of industrial buildings including bridges are listed in Table 1.

An important aspect that is characteristic for industrial heritage and needs to be taken into account is the relation between the structure and the technologies. The load-bearing structure has often been designed in order to meet the specific requirements of implemented technologies. Typical examples include corbels supporting transmissions, crane girders or single-purpose structures such as blast furnaces, mills or headframes.

The heritage values of a building, its structure and associated technologies are defined by preservationists and architects. These values should be taken into account in any plans for the future use of the building and the designing of construction interventions. As a rule, a compromise needs to be found between clients, preservationists, architects and civil engineers, balancing the qualities of the structure with respect to its future use, the viability of the project, total costs and preservation of the heritage values. 
Table 1: Criteria of the heritage value of industrial buildings.

\begin{tabular}{ll}
\hline Criterion & Description \\
\hline $\begin{array}{l}\text { General cultural sig- } \\
\text { nificance for a region }\end{array}$ & $\begin{array}{l}\text { Reflected by the degree under which the building is listed - } \\
\text { regional, national, transnational - UNESCO protected; consid- } \\
\text { erations of urbanistic, architectural, authenticity and structural } \\
\text { integrity aspects. }\end{array}$ \\
\hline Cultural development & $\begin{array}{l}\text { Authenticity, innovativeness, start of phase of industrial develop- } \\
\text { ments, relation to an outstanding person. }\end{array}$ \\
\hline $\begin{array}{l}\text { Technological or tech- } \\
\text { nical significance }\end{array}$ & $\begin{array}{l}\text { Preserved technological cycle, technological equipment as a } \\
\text { part of the structure, uniqueness of technologies, originality, } \\
\text { characteristic and authentic structural system - exceptional span } \\
\text { lengths, novel implementation. }\end{array}$ \\
\hline
\end{tabular}

Table 2: Indicative relation between the heritage value of a building or bridge and the Consequence Class according to EN 1990 [5] - minimum requirement on CC.

\begin{tabular}{|c|c|c|c|}
\hline \multirow{2}{*}{$\begin{array}{l}\text { Technical possibilities of preserving } \\
\text { the heritage value }\end{array}$} & Heritage & \multicolumn{2}{|l|}{ value } \\
\hline & Low & Medium & High \\
\hline Small & $\mathrm{CC} 1$ & $\mathrm{CC} 1$ & $\mathrm{CC} 2$ \\
\hline Medium & $\mathrm{CC} 1$ & $\mathrm{CC} 2$ & $\mathrm{CC} 3$ \\
\hline High & $\mathrm{CC} 2$ & $\mathrm{CC} 3$ & $\mathrm{CC} 3$ \\
\hline
\end{tabular}

Table 2 indicates how heritage value can be taken into account in specifying the Consequence Classes CC in accordance with EN 1990 [5]. It is emphasized that these indications provide a minimum class, i.e. a higher class should be taken into account if needed because of economic or human safety reasons. For more details see [2].

\section{CASE STUDY OF A 19TH-CENTURY SPINNING FACTORY}

\subsection{Introduction}

An important requirement of how to preserve the appearance and materials of heritage structures should be considered in the assessment of existing structures. To retain heritage values, the structure should be preserved, as far as possible, with its original materials and structural concept intact. However, the verification of material properties is difficult in many cases. This is particularly the case of existing cast-iron structures which have material properties significantly different from current structural steels. An example of the assessment and successful reconversion of an existing industrial building is provided in this section.

A spinning mill, located in the city centre of Liberec in North Bohemia, dates from 1868. The factory served its purpose until 1930. The building was then out of use until 1990, when it was converted to a gallery with a coffee bar, and later to a warehouse. After that the building 
had not been used and had gradually deteriorated for several years before the reliability assessment was carried out. Recently, it has been decided to recognize its heritage value, list the building as a regional monument and carry out its rehabilitation. The building with an ornamental façade before rehabilitation is shown in Fig. 1.

The building is intended to be used for residential purposes and as a coffee bar. One of main concerns during the rehabilitation is to preserve the historical character of the building, formed primarily by its cast-iron columns.

\subsection{In-situ inspection and measurements}

The building, made of fired solid bricks, consists of three timber floors supported by cast-iron columns with ornamental heads (Fig. 2), carrying timber beams and timber floors. The wood has been locally attacked by insects or dry rot.

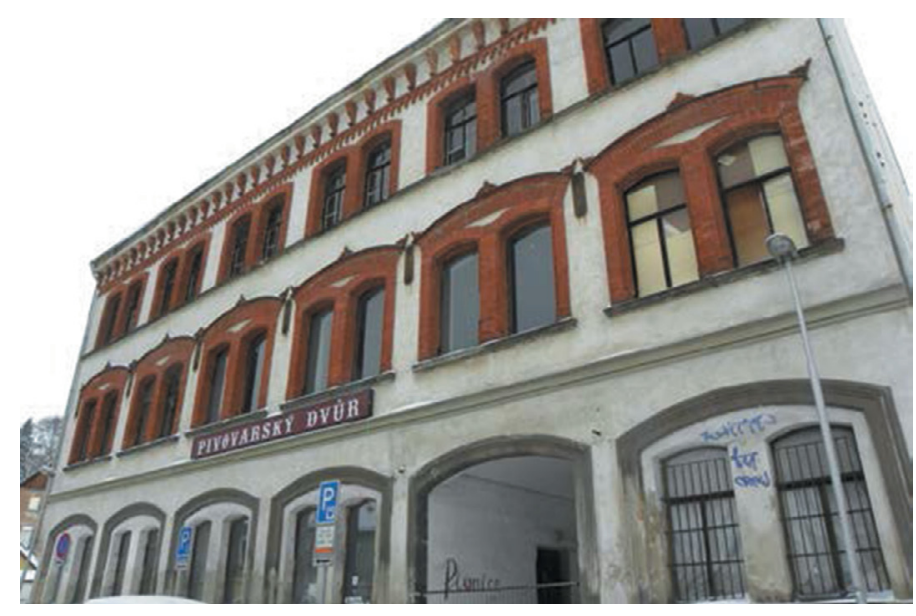

Figure 1: View of the former spinning factory.

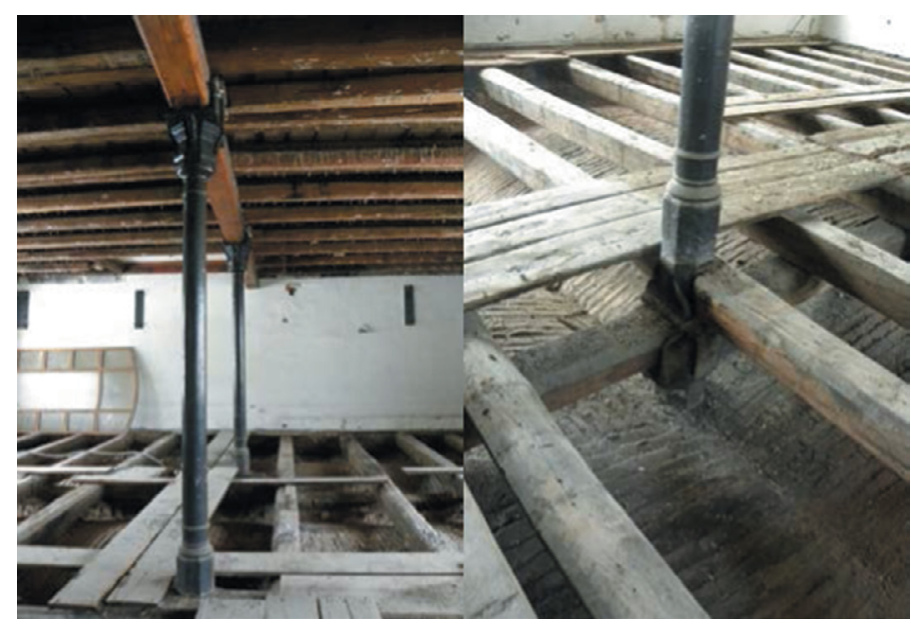

Figure 2: The load-bearing structure with cast-iron columns. 
Table 3: Thickness $t$ of selected columns.

\begin{tabular}{lcccc}
\hline \multirow{2}{*}{$\begin{array}{l}\text { Floor } \\
\text { number }\end{array}$} & $\begin{array}{c}\text { Location of } \\
\text { measurement }(\mathrm{m})\end{array}$ & \multicolumn{3}{c}{ Thickness of column $(\mathrm{mm})$} \\
\cline { 2 - 5 } 1 & 1 & 1 & 2 & 3 \\
\cline { 2 - 5 } & 2 & 17.5 & 18 & 18.3 \\
\hline 2 & 1 & 16 & 15.8 & 14.6 \\
\hline \multirow{2}{*}{3} & 2 & 14.7 & 15.5 & 14.4 \\
\cline { 2 - 5 } & 1 & 17.4 & 17.2 & 16.4 \\
\hline & 2 & 17.1 & 16.8 & 16.1 \\
\hline
\end{tabular}

Visual inspection revealed that masonry walls and cast-iron columns were without any significant damage affecting structural reliability. The geometry of all the cast-iron columns, including their thickness, was measured at heights of 1 and $2 \mathrm{~m}$ above the floor level. The average values for selected columns are given in Table 3 .

Actual thickness of all the columns varies along height and is unexpectedly reduced for all the columns in the second floor. It should be noted that it was very difficult to obtain reliable information about actual geometrical imperfections of the columns.

Grey cast iron is characterized by a high compressive strength and significantly reduced tensile strength caused by a high carbon content of $2-5 \%$. The behaviour of the material is ductile in compression and brittle in tension.

Non-destructive tests of strength of the columns were carried out by a hardness tester TH 130 and then converted to estimates of the ultimate strength in compression. The results indicated that the ultimate strength of the cast iron varied in a rather broad range from 665 to $800 \mathrm{MPa}$; this range is partly attributable to the measurement uncertainty of a nondestructive technique. The material hardness was tested at two levels (1 and $2 \mathrm{~m}$ ) of each column. The characteristic value of ultimate strength was estimated in accordance with EN 1990 [5], Annex D.

For a representative column, the sample mean $m=702 \mathrm{MPa}$ and coefficient of variation $v=$ 0.071 are evaluated from six measurements $(n=6)$, a coefficient $k_{\mathrm{n}}=2.18$ is obtained from EN 1990 [5]. Assuming lognormal distribution, the characteristic value of ultimate strength is then estimated as:

$$
f_{\mathrm{u}, \mathrm{k}}=m \exp \left(-k_{n} v\right)=702 \exp (-2.18 \times 0.071) \approx 600 \mathrm{MPa}
$$

The design value of ultimate strength $f_{\mathrm{u}, \mathrm{d}}$ may be approximately estimated for the column from eqn (4). Considering the coefficient $k_{\mathrm{n}}=6.36$ leads to $f_{\mathrm{u}, \mathrm{d}}=450 \mathrm{MPa}$. The subscripts ' $\mathrm{k}$ ' and ' $\mathrm{d}$ ' denote a characteristic and design value, respectively.

For the ratio $f_{\mathrm{u}} / f_{\mathrm{y}}=2$ between the ultimate compressive strength $f_{\mathrm{u}}$ and yield strength $f_{\mathrm{y}}$ $\left(0.2 \%\right.$ proof stress) [17], the characteristic and design yield strengths are $f_{\mathrm{yk}} \approx 300 \mathrm{MPa}$ and $f_{\mathrm{yd}} \approx 225 \mathrm{MPa}$, respectively. As an approximation, the tensile strength may be considered to be about one third of the compressive strength, i.e. about $75 \mathrm{MPa}$.

Due to the restrictions imposed by preservationists, the results of the non-destructive tests were not calibrated by destructive tensile tests. Only a small sample of the material was extracted for a punching test and microscopic analysis of the material. The prepared material samples were analysed by means of a confocal laser microscope, which confirmed the type 
of cast iron. Black smudges formed by lamellar graphite are characteristic of grey cast iron. This graphite forms voids or cracks within the iron matrix and considerably reduces tensile strength.

The Czech national standard CSN 73 0038:2014 recommends characteristics of cast iron which may be applied for the verification of columns when structure-specific information is unavailable. The design value of yield strength under compression, and also compression strength in combination with bending is estimated by a conservative value of $100 \mathrm{MPa}$; the modulus of elasticity is $100 \mathrm{GPa}$.

\subsection{Reliability verification of columns}

Firstly, the partial factor method - the basic method for reliability verifications in EN 1990 [5] - is applied. For the evaluation of the load-bearing capacity of the columns, actions due to self-weight, permanent actions, imposed and snow loads are estimated. The column on the first floor is additionally loaded by the self-weight of masonry vaults. Imposed loads for residential areas (category A) and two alternatives of a floor structure are considered (alt. Ireinforced concrete slabs, alt. II - composite timber beams and concrete slabs). Snow load is determined according to EN 1991-1-3 [18]. The characteristic value of the ground snow load is $s_{k}=1.5 \mathrm{kN} / \mathrm{m}^{2}$.

Selected results of the analysis of internal forces and utilized capacity (in \%) are presented in Table 4 for specified material characteristics of the in-situ material testing, and in Table 5 for the characteristics of cast iron recommended in CSN 73 0038:2014.

Table 4: Reliability assessment of a column for the design strength $f_{\mathrm{yd}}=190 \mathrm{MPa}$.

\begin{tabular}{lcccc}
\hline Alternative & Floor number & $\begin{array}{c}\text { Design value } \\
\text { of axial force } \\
\text { in kN }\end{array}$ & $\begin{array}{c}\text { Design value of } \\
\text { axial resistance } \\
\text { in kN }\end{array}$ & Utilization in \% \\
\hline \multirow{3}{*}{ I } & 3 & 350 & 405 & 86 \\
\cline { 2 - 5 } & 2 & 627 & 317 & 198 \\
\hline & 1 & 985 & 799 & 123 \\
\hline II & 3 & 199 & 405 & 49 \\
\hline & 2 & 328 & 317 & 104 \\
\hline & 1 & 530 & 799 & 66 \\
\hline
\end{tabular}

Table 5: Reliability assessment of columns for the design strength $f_{\mathrm{yd}}=100 \mathrm{MPa}$.

\begin{tabular}{lcccc}
\hline Alternative & $\begin{array}{c}\text { Floor } \\
\text { number }\end{array}$ & $\begin{array}{c}\text { Design value of axial } \\
\text { force in } \mathrm{kN}\end{array}$ & $\begin{array}{c}\text { Design value of axial } \\
\text { resistance in } \mathrm{kN}\end{array}$ & $\begin{array}{c}\text { Utilization } \\
\text { in \% }\end{array}$ \\
\hline \multirow{3}{*}{ I } & 3 & 350 & 225 & 155 \\
\cline { 2 - 5 } & 2 & 627 & 176 & 356 \\
\hline \multirow{3}{*}{ II } & 1 & 985 & 444 & 222 \\
\cline { 2 - 5 } & 3 & 199 & 225 & 89 \\
\hline & 2 & 328 & 176 & 187 \\
\hline
\end{tabular}


The analysis based on in-situ measurements that the columns need not be strengthened when the composite, lightweight timber-concrete floor is applied (alt. II). When a heavier floor (alt. I) or the material characteristics given in CSN 73 0038:2014 are considered, most columns should be upgraded. Strengthening by casting concrete into the holes of the columns is considered as a common method for which the basic principles are provided in EN 1994-1-1 [19].

However, the efficiency of such strengthening in the case of historic materials like cast iron differs from modern steels, and depends considerably on the interaction between cast iron and concrete. Therefore, further guidance beyond the scope of Eurocodes is needed [20]. It should be mentioned that other methods of strengthening, such as by strips of FRP polymers EN 1998-3 [21], might also be applied. Each method of strengthening has advantages and disadvantages that should be taken into account in conjunction with the aspects of the viability of execution, fire resistance and total costs.

Probabilistic reliability analysis is based on eqns (1) and (2). The limit state function takes into account a combined load effect $E$ and resistance $R$ of a column:

$$
\mathrm{Z}(\mathbf{X})=\theta_{\mathrm{R}} R-\theta_{\mathrm{E}} E
$$

Here $\theta_{\mathrm{R}}$ denotes the uncertainty in the resistance model and $\theta_{\mathrm{E}}$ the uncertainty in the action effect model. The models of basic variables given in Table 6 are based on the JCSS Probabilistic Model Code [10] and recent scientific findings; overview with a special focus on industrial heritage buildings is provided in [2]. The mean $\mu_{X}$ and the standard deviation $\sigma_{X}$ of each variable are related to the characteristic value $X_{k}$. For the reliability analysis of the column, the imposed load is considered as a leading variable action and snow as an accompanying action. Using Turkstra's rule [22], a 50-year maximum of the imposed load is thus combined with an arbitrary point-in-time value of the snow load, approximated here by its annual maximum. More detailed analysis could be based on the approaches to load combination described in [2]. The probabilistic model of $\theta_{\mathrm{R}}$ is based on results of the detailed study focused on uncertainties in predicting compressive resistance of cast-iron columns [23].

Table 6: Models of basic variables.

\begin{tabular}{|l|l|l|l|l|}
\hline Symbol & Variable & Distribution & $\mu_{X} / x_{k}$ & $\begin{array}{l}\text { Standard } \\
\text { devia- } \\
\text { tion } \sigma_{X}\end{array}$ \\
\hline$f_{\mathrm{y}}$ & $\begin{array}{l}\text { Yield strength of cast iron (Section } \\
4.2)\end{array}$ & Lognormal & 1.45 & $0.15 \mu_{X}$ \\
\hline$r$ & Radius of a column & Normal & Measurements & $0.05 \mu_{X}$ \\
\hline$t$ & Thickness of a column (Table 3) & Normal & Measurements & $0.02 \mathrm{~m}$ \\
\hline$\theta_{\mathrm{R}}$ & Resistance model uncertainty & Lognormal & 1 & 0.15 \\
\hline$\theta_{\mathrm{E}}$ & Load effect model uncertainty & Lognormal & 1 & 0.05 \\
\hline$G$ & Permanent action & Normal & Measurements & $0.1 \mu_{X}$ \\
\hline$Q_{\text {imp }}$ & Fifty-year maxima of imposed load & Gumbel & 0.6 & $0.35 \mu_{X}$ \\
\hline$Q_{\text {snow }}$ & $\begin{array}{l}\text { Annual maxima of the snow load on } \\
\text { the roof }\end{array}$ & Gumbel & 0.35 & $0.7 \mu_{X}$ \\
\hline
\end{tabular}


The probabilistic analysis leads to the reliability index $\beta \approx 3.5$ when a reinforced concrete slab is applied (alt. I) and the cast-iron properties updated by testing are considered. When the material properties recommended in CSN 73 0038:2014 are taken into account, the resulting reliability is very low $(\beta=1.5)$. For alt. II the reliability index $\beta=4$ is determined for the updated cast-iron properties.

Consequences of column failure in a residential building are considered as medium, corresponding to the Consequence Class CC2 according to EN 1990 [5]. In following the guidance in Table 2, a minimum consequences class $\mathrm{CC} 2$ is considered:

- The technical possibilities of preserving a heritage value are high as it is relatively easy to strengthen the columns and preserve the authenticity of the building.

- The heritage value of the building is low as it is of regional importance.

That is why CC2, corresponding to the Reliability Class RC2, is considered and the target reliability index $\beta \approx 3.8$ is accepted [5]. The reliability of the structure for alt. II is thus sufficient.

Some uncertainties in actual material properties and geometric imperfections of the castiron columns are not fully included in the reliability analysis. Examples include the uncertainties related to non-inspected columns, missing calibration of non-destructive hardness measurements by tensile tests and boundary conditions of the investigated columns. However, clear evidence that the structure of the spinning mill withstood for more than one hundred years considerably greater imposed loads than presently required for residential purposes should be taken into account. Therefore, taking into account the results of the reliability analyses and the satisfactory past performance of the structure, no strengthening is recommended.

\section{CONCLUDING REMARKS}

1. Reliability verifications of the industrial heritage buildings and other existing structures should be based on results of inspection and on relevant data.

2. Assessments based on simplified conservative procedures used for structural design often lead to expensive upgrades and losses of the heritage value.

3. Probabilistic methods allow to adequately describe uncertainties and take into account results of inspections, tests, measurements and satisfactory past performance of the structure.

4. The target reliability for the assessment of historic structures should reflect their heritage values and the technical possibilities of preserving these values.

5. The case study of a 19th-century spinning factory reveals that:

i. application of the general material properties given in Czech national standards yields unacceptably low structural reliabilities;

ii. when actual geometric and material properties based on experimental data are applied, the reliability of the cast-iron structure columns is acceptable and no intervention is required.

6. Further research should be focused on enhancing the methods for verification of actual properties of cast-iron structures and on improving description of the uncertainties in resistance models of cast-iron structural members. 


\section{ACKNOWLEDGEMENTS}

This study is an outcome of the research project DG16P02M050 'Optimisation of Observations and Assessment of Heritage Structures', supported by the Ministry of Culture of the Czech Republic. It is partly based on the recent conference contributions [12, 24].

\section{REFERENCES}

[1] TICCIH, The Nizhny Tagil Charter for the Industrial Heritage, The International Committee for the Conservation of the Industrial Heritage: Nizhny Tagil, p. 6, 2003.

[2] Sykora, M., Holicky, M., Markova, J. \& Senberger, T., Probabilistic Reliability Assessment of Existing Structures (Focused on Industrial Heritage Buildings), Czech Technical University in Prague, CTU Publishing House: Prague, p. 108, 2016.

[3] Läuferts, M. \& Mavunganidze, J., Ruins of the past: Industrial heritage in Johannesburg. Proceedings of STREMAH XI, ed. C.A. Brebbia, WIT Press: Ashurst Lodge, pp. 533-542, 2009.

[4] JCSS, Probabilistic Assessment of Existing Structures, Joint Committee on Structural Safety, RILEM Publications S.A.R.L.: Bagneux, France, 2001.

[5] EN 1990, Eurocode - Basis of Structural Design, p. 87, 2002.

[6] ISO 13822, Bases for Design of Structures - Assessment of Existing Structures, p. 44, 2010.

[7] Luechinger, P., Fischer, J., Chrysostomou, C., Dieteren, G., Landon, F., Leivestad, S. et al, New European Technical Rules for the Assessment and Retrofitting of Existing Structures (JRC Science and Policy Report), JRC: p. 125, 2015.

[8] Ellingwood, B.R., Reliability-based condition assessment and LRFD for existing structures. Structural Safety, 18(2-3), pp. 67-80, 1996. DOI: 10.1016/0167-4730(96)00006-9.

[9] ISO 12491, Statistical Methods for Quality Control of Building Materials and Components, p. 30, 1997.

[10] JCSS, JCSS Probabilistic Model Code (periodically updated, online publication), Joint Committee on Structural Safety: 2001.

[11] Sykora, M., Holicky, M. \& Diamantidis, D., Probabilistic updating in the reliability assessment of industrial heritage structures. Heron, 59(2/3), p. 9, 2015.

[12] Sykora, M. \& Holicky, M., Probabilistic reliability assessment of industrial heritage case study of a factory for boiler production. Proceedings of STREMAH 2013, ed. C.A. Brebbia, WIT Press: Ashurst Lodge, pp. 171-182, 2013.

[13] Sykora, M., Holicky, M. \& Jung, K., Updating in the probabilistic assessment of existing structures. Transactions of the VSB - Technical University of Ostrava, Civil Engineering Series, XII(2), pp. 205-215, 2013. DOI: 10.7441/joc.2013.03.07.

[14] ISO 2394, General Principles on Reliability for Structures, p. 111, 2015.

[15] Steenbergen, R.D.J.M., Sykora, M., Diamantidis, D., Holicky, M. \& Vrouwenvelder, A.C.W.M., Economic and human safety reliability levels for existing structures. Structural Concrete, 16(September 2015), pp. 323-332, 2015. DOI: 10.1002/ suco.201500022.

[16] Sykora, M., Holicky, M., Jung, K. \& Diamantidis, D., Target reliability for existing structures considering economic and societal aspects (accepted for publication). Structure and Infrastructure Engineering, 2016.

[17] Rondal, J. \& Rasmussen, K.J.R., On the strength of cast iron columns. Journal of Constructional Steel Research, 60(9), pp. 1257-1270, 2004. DOI: 10.1016/j. jesr.2003.12.006. 
[18] EN 1991-1-3, Eurocode 1: Actions on Structures - Part 1-3: General Actions; Snow Loads, 2003.

[19] EN 1994-1-1, Eurocode 4: Design of Composite Steel and Concrete Structures - Part 1-1: General Rules and Rules for Buildings, 2004.

[20] Heyde, S. \& Geissler, K., Strength of concrete filled historic cast-iron columns. Composite Construction in Steel and Concrete VI, eds. R.T. Leon, T. Perea, G.A. Rassati \& J. Lange, American Society of Civil Engineers: Reston, VA, pp. 304-316, 2011.

[21] EN 1998-3, Eurocode 8: Design of Structures For Earthquake Resistance, Part 3: Assessment and Retrofitting of Buildings, p. 89, 2005.

[22] Turkstra, C.J., Theory of Structural Design Decisions, Solid Mechanics Division, University of Waterloo: Ontario, Canada, 1970.

[23] Brych, I., Holicky, M., Jung, K. \& Sykora, M., Uncertainty in resistance models for historic cast-iron columns (invited lecture at Int. Conf. STREMAH 2015). Proceedings of SUSTAINABLE CITY X, eds. C.A. Brebbia \& W.F. Florez-Escobar, WIT Press: Ashurst Lodge, pp. 473-482, 2015.

[24] Markova, J., Holicky, M., Jung, K., Podstawka, A. \& Bures, V., Reliability assessment of cast-iron heritage structures. Proceedings of ESREL 2014, eds. T. Nowakowski, M. Mlynczak, A. Jodejko-Pietruczuk. \& S. Werbinska-Wojciechowska, Taylor and Francis/ Balkema: Leiden, pp. 2201-2205, 2015. 